in addressing harmful consumption, whilst enabling the maintenance of social support.

\section{P09 RANDOMISED CONTROLLED TRIALS OF COMMUNITY- BASED PHYSICAL ACTIVITY INTERVENTIONS IN ADULTS WITH LONG-TERM FOLLOW-UP AND OBJECTIVE PHYSICAL ACTIVITY MEASUREMENTS: A SYSTEMATIC REVIEW AND META-ANALYSIS}

${ }^{1} \mathrm{C}$ Wahlich, ${ }^{1} \mathrm{U}$ Chaudhry, ${ }^{1} \mathrm{R}$ Normansell, ${ }^{1} \mathrm{D}$ Cook*, ${ }^{2} \mathrm{~S}$ Hirani, ${ }^{1} \mathrm{R}$ Knightly, ${ }^{1} \mathrm{~T}$ Harris. ${ }^{1}$ Population Health Research Institute, St George's, University of London, London, UK; ${ }^{2}$ School of Health Sciences, City, University of London, London, UK

10.1136/jech-2019-SSMabstracts. 160

Background Physical inactivity is a global public health concern. Systematic review evidence indicates interventions can increase short-term physical activity (PA) levels. However, long-term health benefits require sustained increases in PA levels, and evidence from interventions with objective PA measures beyond 12-months is lacking. This review aims to:

1. Identify and describe randomised controlled trials (RCTs) in adults with objective PA measures and long-term follow-up (beyond 12-months)

2. Evaluate the extent to which intervention effects are sustained beyond 12-months

Methods We systematically searched seven databases using $\mathrm{MeSH}$ headings and keywords to identify RCTs published after 01/01/2000. We included trials reporting long-term effects ( $\geq 12$-months) on objective PA levels with communitybased participants, aged $\geq 18$ years, with no specific medical conditions. We conducted quality assessments and meta-analyses at different follow-up points.

Results Of 17233 unique records identified, 9 studies were included in the review, 5 in the meta-analyses. Long-term follow-up ranged from 12-months to 4-years. We observed increases in PA at 12-months for steps/day (mean difference (md) $=554,95 \% \mathrm{CI}=383$ to 724$)$ and weekly minutes of moderate-to-vigorous PA (MVPA) $(\mathrm{md}=34.9,95 \% \mathrm{CI}=26.9$ to 42.8). This increase was sustained up to 4 years for both steps/day ( $\mathrm{md}=494,95 \% \mathrm{CI} 251$ to 738 ) and weekly minutes of MVPA ( $\mathrm{md}=25.2,95 \% \mathrm{CI}=13.3$ to 37.1 ).

Conclusion There are few PA interventions with objective follow up beyond 12-months. This review provided evidence of sustained PA intervention effects beyond 12-months and up to 4-years for both steps/day and MVPA.

\section{P10 COMMUNICATION IS THE ROOT ISSUE: INFORMING THE} DEVELOPMENT OF CYBERBULLYING INTERVENTIONS

${ }^{1} \mathrm{R}$ Dennehy*, ${ }^{2} \mathrm{~S}$ Meaney, ${ }^{1}$ Mary Cronin, ${ }^{1,3}$ Ella Arensman. ${ }^{1}$ School of Public Health, University College Cork, Cork, Ireland; ${ }^{2}$ National Perinatal Epidemiology Centre, University College Cork, Cork, Ireland; ${ }^{3}$ National Suicide Research Foundation, University College Cork, Cork, Ireland

\subsection{6/jech-2019-SSMabstracts. 161}

Background Cyberbullying is an international public health concern. The potential cost to the physical and mental health of young people calls for action to address this issue. Guided by the UK Medical Research Council guidance on complex interventions and the Behaviour Change Wheel, an approach for applying behavioural theory to intervention development, the aim of this study was to conceptualise cyberbullying from the perspective of post-primary school students to inform the development of an intervention to address the issue.

Methods A systematic review and meta-ethnographic synthesis of qualitative studies related to young people's perceptions of cyberbullying was conducted. A young person's advisory group (aged 16) was established to collaborate with researchers in the design and conduct of a qualitative study across four postprimary schools. 11 focus groups $(n=64)$ were conducted with young people aged 14-17. Data was analysed thematically and the findings were interpreted by the advisory group. Results The advisory group identified key areas requiring intervention: parental knowledge of the cyber world; parental reaction when approached for help; bodily autonomy (with regard to the sharing of nude images); mental health. They identified 'communication' as the 'root issue' in tackling these issues: communication between young people and parents; communication among peers; and communication in the delivery of prevention and intervention programmes for young people.

Conclusion This study provides a thorough understanding of cyberbullying from the perspective of young people. The findings will be used to design, implement, and evaluate interventions that are grounded in young people's experience.

\section{P11 THE ASSOCIATION OF ALCOHOL PRS ON MENTAL HEALTH PHENOTYPES: A PHEWAS IN THE AVON LONGITUDINAL STUDY OF PARENTS AND CHILDREN (ALSPAC)}

${ }^{1,2}$ KE Easey*, 1,2 E Haan, 1,2 L Schellas, 1,2 H Sallis, 1,2R Wootton, 1,2MR Munafò, ${ }^{3} \mathrm{NJ}$ Timpson, ${ }^{2,3} \mathrm{~L}$ Zuccolo. 'School of Psychological Science, University of Bristol, Bristol, UK; ${ }^{2}$ MRC Integrative Epidemiology Unit, University of Bristol, Bristol, UK; ${ }^{3}$ Department of Population Health Sciences, University of Bristol, Bristol, UK

\subsection{6/jech-2019-SSMabstracts.162}

Background An emerging technique is a Phenome Wide Association Study (PheWAS), which reverses the phenotype to genotype methods used within a GWAS, instead taking a predetermined set of genetic variants, and testing which of a wide range of phenotypes these genetic variants may be associated with. We can further investigate the genetic architecture of multiple traits and disease outcomes through linking a chosen genetic variant to multiple phenotypes, in varying populations.

In this study we constructed polygenic risk scores (PRS) from single nucleotide polymorphisms (SNPs) shown to be robustly related to alcohol use, to test:

1. These genetic signals within two sub populations of adolescents, and for pregnant women.

2. If there are any associations (other than with alcohol use) of these PRS with many mental health phenotypes.

3. Intrauterine effects of Maternal PRS for alcohol use for associations with offspring phenotypes.

Methods Participants were mothers and offspring from the Avon Longitudinal Study of Parents and Children (ALSPAC). Participants were genotyped and PRS were constructed based on genome-wide significant SNPs for alcohol consumption. Targeted phenotypes were selected from substance use $(n=22)$ and mental health/behavioural variables $(n=91)$ within ALSPAC. Linear and logistic regression analyses were used to investigate if PRS for alcohol use were associated with alcohol use (mothers in pregnancy; children) and health phenotypes 